\title{
Therapeutic potential of traditionally used medicinal plant Andrographis paniculata (Burm. F.) against diabesity: An experimental study in rats
}

\author{
Ajit Kumar Thakur ${ }^{1}$, Shyam Sunder Chatterjee ${ }^{2}$, Vikas Kumar ${ }^{1, *}$ \\ ${ }^{I}$ Neuropharmacology Research Laboratory, Department of Pharmaceutics, Indian Institute of Technology (Banaras Hindu \\ University), Varanasi-221 005, India ${ }^{2}$ Stettiner Straße 1, Karlsruhe, Germany
}

\begin{abstract}
Metabolic effects of ten daily doses of standardized extract of Andrographis paniculata leaves (AP) rich in andrographolide were evaluated in a rat model of type- 2 diabetes and in diet induced obese rats. AP was administered per-orally as suspension in $0.3 \%$ carboxymethylcellulose at doses of 50, 100 and 200 $\mathrm{mg} / \mathrm{kg} /$ day for 10 consecutive days. Blood glucose, insulin and lipid profile of rats were measured by using enzyme kits. In addition, effects of such treatments on anti-oxidant enzymes activity and histopathological changes in various organs of diabetic rats were assessed. AP treatments reversed body weight losses and increased plasma insulin level in diabetic rats. The anti-oxidant enzymes activity became normal and histopathological changes observed in pancreas, liver, kidney and spleen of diabetic animals were less severe in extract treated groups. On the other hand, hyperinsulinemia and increased body weight gains observed in high fat or fructose fed rats were less severe in the extract treated groups. These observations revealed therapeutic potentials of the extract for treatments of diabesity associated metabolic disorders, and suggest that the effects of the extract on insulin homeostasis depend on the metabolic status of animals. Activation of cytoprotective mechanisms could be involved in its mode of action.
\end{abstract}

Keywords diabetes, obesity, insulin homeostasis, oxidative damage, organ pathologies

\section{INTRODUCTION}

Andrographis paniculata (Burm. F.) Wall. Ex Nees is an extremely bitter in taste, traditionally used medicinal herb now attracting considerable attention of modern drug discoverers for obtaining structurally and functionally novel therapeutic leads against cancer and inflammatory diseases (Chao and Lin, 2010; Lim et al., 2012). However, various other medicinal values of different types of concoctions of the plant have been known to practitioners of traditionally known medical systems in many Asiatic countries, and during more recent decades broad spectrums of therapeutically interesting bioactivities of diverse types of Andrographis paniculata extracts and some of their constituents have also been identified (Subramanian et al., 2012). In Traditional Chinese Medicine, Andrographis paniculata is indicated for conditions of "heat," particularly in the lungs, throat, and urinary tract, as well as for manifestations of "Fire Poison" on the skin, such as sores and carbuncles (Bensky and Gamble, 1986). In Korea this plant is known as Cheonshimryeon and in China as Chuan Xin Lian, and has been traditionally prescribed for rheumatoid arthritis, inflammation, cold, fever, and diarrhea (Burgos et al., 2009; Chandrasekaran et al., 2010; Shen et al., 2013). In Ayurveda the plant is classified as a Rasayana herb (Govindarajan et al.,

*Correspondence: Vikas Kumar

E-mail: vikas.phe@iitbhu.ac.in

Received January 3, 2014; Accepted February 13, 2014; Published

February 28, 2014

doi: http://dx.doi.org/10.5667/tang.2014.0001

(C)2014 by Association of Humanitas Medicine

This is an open access article under the CC BY-NC license.

(http://creativecommons.org/licenses/by-nc/3.0/)
2005; Thakur et al., 2012), and it is often included as an active ingredient in numerous currently commercialized Ayurvedic formulations. Traditionally, a decoction of leaves is used in dyspepsia and a tincture of the root as a tonic, stimulant and aperients. It is also useful in wounds, ulcers, chronic fever and malaria (Al-Bayaty et al., 2012; Mishra et al., 2009). Many Ayurvedic Rasayana herbs have been reported to possess antidepressant, anxiolytic, cognitive function improving and diverse other psychopathologies. Since co-morbidities of such psychopathologies are often encountered in patients suffering from chronic diseases, we try to obtain an analytically and pharmacologically well characterized Andrographis paniculata extract that could be used for combating such co-morbidities. For such purposes, an Ayurveda centered holistic pharmacological strategy evolving from observations made with other Ayurvedic herbs in our laboratory and elsewhere is being used (Chatterjee and Kumar, 2012).

Initial observations made in our laboratories have revealed that repeated daily administration of a medicinally used Andrographis paniculata extract (hereafter referred to as AP) can modulate central sensitivity to stress, and that suppression of central dopaminergic mechanisms could be involved in its mode of action (Thakur et al., 2013). It is now becoming increasingly apparent that central dopaminergic system is an integral part of metabolic signaling, and that alterations in sensitivity of this system is involved in etiology, pathogenesis and progression of obesity associated medical conditions (Beeler et al., 2012). Obesity is a risk factor not only for diabetes and other metabolic disorders, but also for numerous other life threatening non-communicable diseases including cardiovascular diseases, cancer and dementia. The term diabesity was initially coined during 1970 s to describe strong 
pathogenic links between type-2 diabetes and obesity (Sims et al., 1973), and it is now well recognized that diabesity is the spreading epidemic of the $21^{\text {st }}$ century (Farag and Gaballa, 2011). However, despite extensive efforts, as yet no very effective, or universally acceptable, therapeutic strategy for prevention of this co-morbid condition has evolved (Colagiuri, 2010).

Although during more recent years a few reports revealing anti-hyperglycemic activity of diverse types of Andrographis paniculata extracts in animal models have appeared (Agarwal et al., 2005; Nugroho et al., 2012; Subramanian et al., 2008; Xu et al., 2012), as yet little attention has been paid to their therapeutic potentials for combating diverse other pathologies commonly encountered in obese patients. In view of the situation, it was of interest to test whether AP by virtue of its anti-stress and anti-dopaminergic activities could as well be a starting point for obtaining a therapeutic lead, or a phytopharmaceutical, potentially useful for combating diverse spectrums of obesity associated pathologies. Results of the very first set of experiments conducted to achieve such goals are described and discussed in this communications. Ultimate goals of the reported experiments were to compare the efficacy of AP in normalizing hyperglycemia and hyperlidemiain a rat model of type-2 diabetes and in high fat fed, or fructose fed obese rats, and to experimentally verify the possibility that reduction of cytotoxic oxidative stress is involved in its observed antidiabetics like efficacy in animal models.

\section{MATERIALS AND METHODS}

\section{Plant extract and analytical characterization}

The plant material was identified as Andrographis paniculata (Burm. F.) Wall. Ex Nees by in-house botanist at R\&D Center of Natural Remedies Pvt. Ltd., Bangalore, India, and a voucher herbarium specimen (No: NR582) is available in their laboratories. Details of extraction procedure and analytical method used for standardizing of the tested extract have been reported elsewhere (Chandrasekaran et al., 2009; Chand rasekaran et al., 2010). Briefly, extraction of Andrographis paniculata coarse ground leaves was done with methanol for 3 $\mathrm{h}$, in a stainless steel jacketed extractor fitted with reflux condenser. The liquid extract was removed and the remaining raw material was re-extracted two more times with methanol in a similar manner. The resulting extracts were combined, concentrated and dried under vacuum $\left(\right.$ at $\left.<55^{\circ} \mathrm{C}\right)$. The yield of the dried extract was $6 \%(\mathrm{w} / \mathrm{w})$. After extraction with methanol, the left over raw material was extracted with water for $3 \mathrm{~h}$ under reflux conditions. This water extract was separated and concentrated under vacuum at around $75^{\circ} \mathrm{C}$ followed by spray drying. Two parts of methanolic and one part of successive water extract were blended to get AP. Analytically, the extract contained andrographolide (>30.0\%, w/w), isoandrographolide (>0.3\%, w/w), neoandrographolide $(>1.0 \%, \mathrm{w} / \mathrm{w})$, androgra panin (> $0.3 \%, \quad w / w)$, and 14-deoxy-11,12 didehydro andrographolide $(<5.0 \%$, w/w) (Chandrasekar an et al., 2009).

\section{Animals}

Adult Charles Foster rats $(150 \pm 10 \mathrm{~g})$ of both sexes were obtained from Central Animal House of Institute of Medical Sciences, Banaras Hindu University, Varanasi, India (Registration Number: 542/AB/CPCSEA). They were housed in groups of six in polypropylene cages at an ambient

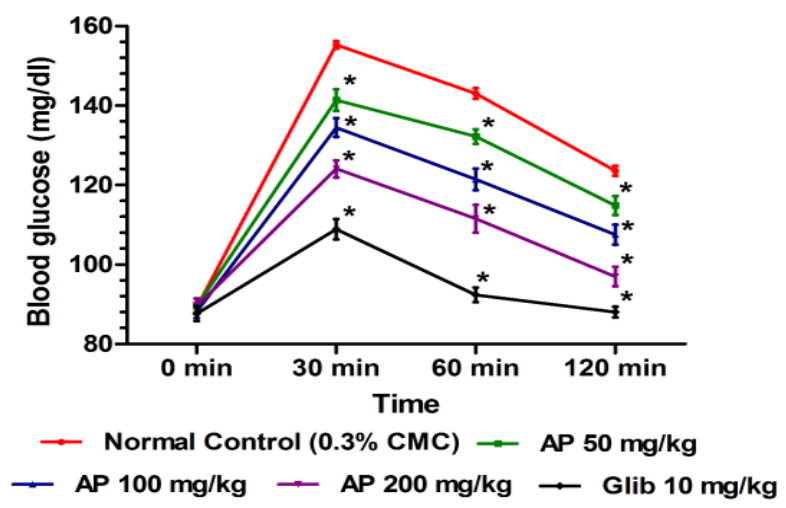

Fig. 1. Effect of Andrographis paniculata on blood glucose level of rats in oral glucose tolerance test. AP: Andrographis paniculata; Glib: Glibenclamide. ${ }^{*} p<0.05$ vs. normal control

temperature of $25 \pm 1^{\circ} \mathrm{C}$ and $45-55 \%$ relative humidity, with a 12:12 h light/dark cycle. Except stated otherwise, they were always provided with commercial Normal Pellet Diet (NPD; Amrut Laboratory Animal Feed; Pranav Agro Industries Ltd., Sangali, India) and water ad libitum, and were acclimatized to laboratory conditions for one week before using them for the experiments. Principles of laboratory animal care (NIH publication $85-23$, revised in 1985) guidelines were strictly followed, and prior approval from the Central Animal Ethical Committee of the University was obtained (Dean/11$12 / \mathrm{CAEC} / 325$, dated November 30, 2011$)$.

\section{Animal grouping and drug administration}

For each series of experiments, six experimental groups consisting of equal ratio of male and female (12 animal each in 2 control groups and 6 animals each in 4 drug treatment groups) were used. Normal and negative control (diabetic and obese) groups were per-orally treated with $0.3 \%$

Table 1. Effect of Andrographis paniculata on body weight, fasting blood glucose and plasma insulin levels of the experimental groups observed 10 days after daily oral treatments

\begin{tabular}{|c|c|c|c|}
\hline Treatment Group & Body weight change (g) & Fasting blood glucose (mg/dl) & Plasma insulin $(\mu \mathrm{U} / \mathrm{ml})$ \\
\hline Normal Control $(0.3 \%$ CMC $)$ & $5.00 \pm 0.30$ & $89.68 \pm 1.53$ & $17.86 \pm 0.29$ \\
\hline Diabetic Control (0.3\% CMC) & $-7.67 \pm 0.62^{*}$ & $290.43 \pm 1.45^{*}$ & $9.95 \pm 0.15^{*}$ \\
\hline Diabetic + AP $50 \mathrm{mg} / \mathrm{kg}$ & $2.00 \pm 0.37^{¥}$ & $172.80 \pm 2.24^{¥}$ & $11.98 \pm 0.27^{*}$ \\
\hline Diabetic + AP 100 mg/kg & $2.50 \pm 0.50^{¥}$ & $146.18 \pm 1.78^{*}$ & $12.88 \pm 0.21^{*}$ \\
\hline$\overline{\text { Diabetic + AP } 200 \mathrm{mg} / \mathrm{kg}}$ & $4.17 \pm 0.91^{*}$ & $130.43 \pm 2.53^{*}$ & $14.93 \pm 0.15^{*}$ \\
\hline Diabetic + Glib $10 \mathrm{mg} / \mathrm{kg}$ & $7.33 \pm 1.09^{\ddagger}$ & $117.53 \pm 3.08^{*}$ & $16.73 \pm 0.20^{*}$ \\
\hline
\end{tabular}

AP: Andrographis paniculata; Glib: Glibenclamide. ${ }^{*} p<0.05$ vs. normal control, ${ }^{\ddagger} p<0.05$ vs. diabetic control. 
carboxymethylcellulose (CMC) suspension (vehicle) for ten consecutive days. For oral treatments AP was suspended in the vehicle, and 50,100, and $200 \mathrm{mg} / \mathrm{kg} /$ day doses of the extract were administered for 10 consecutive days. Choices of this dose and treatment regimen were based on the observations made earlier in our laboratories with the same extract sample. A positive control group treated similarly either with glibenclamide (Cipla, India; $10 \mathrm{mg} / \mathrm{kg} /$ day), or with atorvastatin (Cipla, India; $10 \mathrm{mg} / \mathrm{kg} /$ day), was always run in parallel in a given set of experiment.

\section{Oral glucose tolerance test}

In this test the effects of ten daily oral doses $(50,100$, and 200 $\mathrm{mg} / \mathrm{kg} / \mathrm{day}$ ) of AP and that of the standard anti-diabetic drug glibenclamide $(10 \mathrm{mg} / \mathrm{kg} / \mathrm{day})$ were compared. Thirty minutes after the last treatments on day 10 all animals were challenged with an oral dose of $2 \mathrm{~g} / \mathrm{kg}$ of glucose. Blood glucose levels were measured immediately before glucose challenge and 30 , 60 and $120 \mathrm{~min}$ thereafter. Hereupon blood was obtained by retro-orbital sampling technique, and an enzymatic method was used to measure glucose concentration (du Vigneaud and Karr, 1925).

\section{Type-2 diabetes model}

Non Insulin Dependent Diabetes Mellitus (NIDDM/type-2) was induced in overnight fasted animals by a single intra peritoneal (i.p.) injection of $65 \mathrm{mg} / \mathrm{kg}$ streptozotocin (STZ; Sigma, India), $15 \mathrm{~min}$ after the i.p. administration of $120 \mathrm{mg} / \mathrm{kg}$ nicotinamide (SD Fine-Chemical Ltd., India) as described by Masiello et al. (1998) with some modifications. Animal was returned to their cages and provided normal food and $10 \%$ sucrose water to minimize hypoglycemic shock. Hyperglycemia was confirmed by elevated glucose level in the blood, determined at 72 hour and then on day 7 after STZ injection (Wu and Huan, 2008). Preselected diabetic animals with blood glucose levels higher than $250 \mathrm{mg} / \mathrm{dl}$ were used in the experiments. Body weight changes of experimental animals occurring during the 10-day treatment period were recorded, and thereafter they were fasted overnight for obtaining blood, liver, kidney, and pancreas samples for biochemical and histological analysis using the methods described later. For comparison sake of comparison a group treated with glibenclamide was run in parallel.

\section{High fat fed obesity model}

Rats were maintained on normal pallet diet (NPD) for one week before the start of the experiment. After one week acclimatization, they were randomly assigned into normal control and obese groups. The normal control group was further maintained on NPD, whereas obese groups were supplied with high fat diet (HFD) for 15 days. Details of the experimental procedure used for obtaining high fat fed obese rats have been described elsewhere (Husain et al., 2011; Srinivasan et al., 2005). Rats showing significant weight gain on HFD (as compared to NPD fed normal control animals) were regrouped for treatments with the vehicle or with AP (50, 100, and 200 $\mathrm{mg} / \mathrm{kg} /$ day $)$, or with atorvastatin $(10 \mathrm{mg} / \mathrm{kg} /$ day $)$. Daily treatments were given for 10 consecutive days starting on day 16 of the experiment. Body weights were recorded daily, and after the last treatment day all animals were fasted overnight for obtaining blood samples used for biochemical analysis. Average food intake by each group on day 15 and 25 of the experiment were recorded.
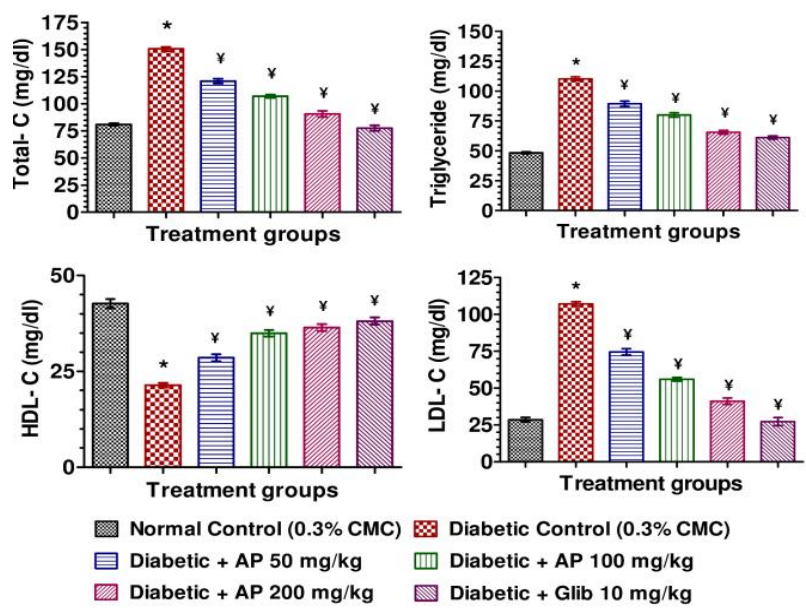

Fig. 2. Effects of 10 consecutive daily oral doses of Andrographis paniculata, or of glibenclamide, on plasma lipid profiles of type-2 diabetic rats. AP: Andrographis paniculata; Glib: Glibenclamide. ${ }^{*} p<$ 0.05 vs. normal control, ${ }_{p}^{\ddagger}<0.05$ vs. diabetic control.

\section{Fructose fed obesity model}

Rats were maintained on normal pellet diet (NPD) and 20\% fructose in drinking water for 15 days according to the procedure described elsewhere (Husain et al., 2011a; Jalal et al., 2007). Rats showing significant weight gain compared to normal rats, were divided into different treatment groups. During the subsequent ten day treatment period they continued to receive NPD and $20 \%$ fructose in drinking water till day 25 . The vehicle treated normal control group was maintained on NPD and normal drinking water throughout the study period. Body weights of the animals were recorded daily and the volume of drinking water consumed by each group on days 15 and 25 of the experiment were noted. Like in other experiments blood samples for biochemical analysis were obtained after

Table 2. Effects of Andrographis paniculata or of glibenclamide treatments on oxidative status of liver, kidney, and pancreas of diabetic rats

\begin{tabular}{|c|c|c|c|c|c|c|c|c|c|}
\hline \multirow{2}{*}{$\begin{array}{l}\text { Treatment } \\
\text { Groups }\end{array}$} & \multicolumn{3}{|c|}{ LPO (nmol MDA/mg of protein) } & \multicolumn{3}{|c|}{ SOD (Units/mg of protein) } & \multicolumn{3}{|c|}{ CAT ( $\mu$ mole $\mathrm{H}_{2} \mathrm{O}_{2} / \mathrm{min} / \mathrm{mg}$ of protein) } \\
\hline & Liver & Kidney & Pancreas & Liver & Kidney & Pancreas & Liver & Kidney & Pancreas \\
\hline $\begin{array}{l}\text { Normal Control } \\
(0.3 \% \text { CMC })\end{array}$ & $9.16 \pm 0.58$ & $9.31 \pm 0.44$ & $5.51 \pm 0.24$ & $13.81 \pm 0.67$ & $18.03 \pm 0.87$ & $4.70 \pm 0.29$ & $18.61 \pm 0.68$ & $14.02 \pm 0.59$ & $12.54 \pm 0.39$ \\
\hline $\begin{array}{l}\text { Diabetic Control } \\
(0.3 \% \text { CMC })\end{array}$ & $14.90 \pm 0.74^{*}$ & $20.65 \pm 0.91^{*}$ & $11.70 \pm 0.53^{*}$ & $5.91 \pm 0.32^{*}$ & $10.02 \pm 0.40^{*}$ & $1.67 \pm 0.16^{*}$ & $10.48 \pm 0.49^{*}$ & $7.92 \pm 0.34^{*}$ & $5.23 \pm 0.29^{*}$ \\
\hline $\begin{array}{l}\text { Diabetic + AP } 50 \\
\mathrm{mg} / \mathrm{kg}\end{array}$ & $11.85 \pm 0.69^{¥}$ & $16.48 \pm 0.81^{¥}$ & $9.86 \pm 0.79^{¥}$ & $8.02 \pm 0.46^{¥}$ & $12.58 \pm 0.97^{¥}$ & $2.23 \pm 0.18^{*}$ & $12.94 \pm 0.94^{¥}$ & $9.96 \pm 0.39^{¥}$ & $7.45 \pm 0.32^{¥}$ \\
\hline $\begin{array}{l}\text { Diabetic + AP } \\
100 \mathrm{mg} / \mathrm{kg}\end{array}$ & $9.57 \pm 0.57^{¥}$ & $13.38 \pm 0.66^{¥}$ & $7.52 \pm 0.58^{*}$ & $8.77 \pm 0.51^{¥}$ & $14.81 \pm 1.02^{¥}$ & $3.12 \pm 0.31^{¥}$ & $14.25 \pm 0.98^{¥}$ & $11.58 \pm 0.58^{¥}$ & $9.51 \pm 0.59^{¥}$ \\
\hline $\begin{array}{l}\text { Diabetic + AP } \\
200 \mathrm{mg} / \mathrm{kg}\end{array}$ & $7.93 \pm 0.42^{¥}$ & $10.91 \pm 0.56^{¥}$ & $5.84 \pm 0.46^{\ddagger}$ & $12.73 \pm 0.75^{¥}$ & $17.11 \pm 1.16^{¥}$ & $4.21 \pm 0.48^{*}$ & $17.67 \pm 0.75^{¥}$ & $13.07 \pm 0.58^{¥}$ & $11.85 \pm 0.72^{\ddagger}$ \\
\hline $\begin{array}{l}\text { Diabetic + Glib } \\
10 \mathrm{mg} / \mathrm{kg}\end{array}$ & $8.59 \pm 0.57^{¥}$ & $11.64 \pm 0.61^{¥}$ & $6.56 \pm 0.54^{¥}$ & $10.64 \pm 0.78^{¥}$ & $15.32 \pm 0.99^{¥}$ & $3.53 \pm 0.40^{¥}$ & $15.07 \pm 0.64^{¥}$ & $11.47 \pm 0.72^{¥}$ & $10.48 \pm 0.45^{\ddagger}$ \\
\hline
\end{tabular}

AP: Andrographis paniculata; Gib: Glibenclamide. ${ }^{*} p<0.05$ vs. normal control, ${ }^{\ngtr} p<0.05$ vs. diabetic control. 
overnight fasting.

\section{Biochemical estimation}

Blood samples were withdrawn from retro-orbital venous plexus on next day of last treatment after appropriate whole night fasting. Plasma was separated from blood in centrifuge at $3000 \mathrm{rpm}(845 \mathrm{x} \mathrm{g}), 5^{\circ} \mathrm{C}$ for 5 minute (Compufuge CPR-30, with Rotor No. 8; REMI, India) and plasma (clear supernatant fluid) was kept in freeze till biochemical estimation. Fasting plasma glucose level was estimated by using biochemical enzyme test kit based on GOD-POD method (Span Diagnostic Ltd., India). Plasma total cholesterol, high density lipoproteincholesterol (HDL-C), and triglycerides were estimated using biochemical enzyme test kits (Span Diagnostic Ltd., India) (Husain et al., 2011a). Low density lipoprotein-cholesterol (LDL-C) was calculated using Friedewald's equation (Friedewald et al., 1972). Plasma insulin level was estimated using Enzyme-Linked Immunosorbent Assay (ELISA) test kit (DRG Instruments GmbH, Germany) as described by Husain et al. (2011b). All biochemical analysis were done by using absorbance microplate reader (iMark ${ }^{\mathrm{TM}}$ - Bio-Rad Laboratories, California) according to instruction manual of respective enzyme test kit.

After collection of blood sample, type-2 diabetic rats were sacrificed and liver, kidney, pancreas were isolated to measure their contents in lipid peroxides (Ohkawa et al., 1979), super oxide dismutase (Kakkar et al., 1984), and catalase (Luck, 1973). The experimental procedures used for such purposes are described in details in the references mentioned.

\section{Histological examinations}

Tissue slices of liver, kidney, pancreas, and spleen obtained from type- 2 diabetes animals were fixed in $10 \%$ formalin and embedded in paraffin wax. Sections of 5 micron thickness were made using a microtome and stained with haematoxylin-eosin (H\&E). For analysis, photographs of each of the slide were taken at $100 \mathrm{X}$ magnification under microscope (Nikon E200Trinocular Microscope, Japan).

\section{Statistical analysis}

Mean \pm SEM was calculated for the observed values in each experimental group. Statistical analysis was performed by one way analysis of variance (ANOVA) followed by StudentNewman-Keuls multiple comparison test (Two-way ANOVA followed by Bonferroni post tests for oral glucose tolerance test). GraphPad Prism 5 was used for statistical analysis. A pvalue less than 0.05 were considered as statistically significant.

\section{RESULTS}

\section{Oral glucose tolerance test}

No statistically significant effects of AP or of glibenclamide treatments on body weight gains of normal laboratory rats during the treatment period were observed (results not shown). Dose-dependent effect of AP was observed $30 \mathrm{~min}$ after the oral glucose administration compared to control rats $(p<0.05)$. Blood glucose levels of different groups observed immediately before oral glucose load and 30,60 and 120 min thereafter are summarized in Fig. 1.

\section{Type-2 diabetes model}

Mean body weights, fasting blood glucose, and plasma insulin levels of the different drug or vehicle treated diabetic groups on the first treatment day were not significantly different from each other (data not shown). During the ten day treatment

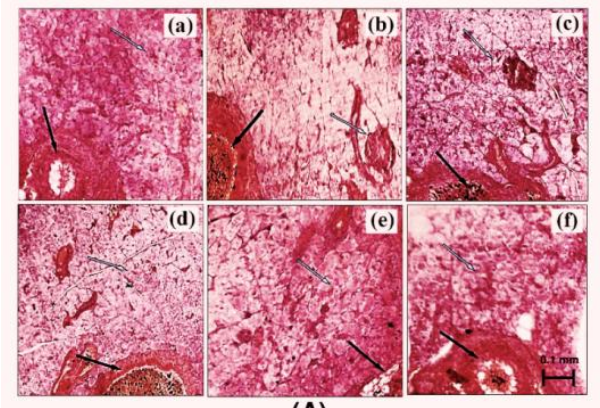

(A)

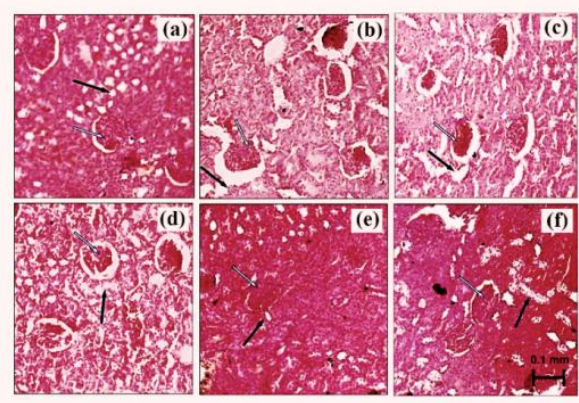

(C)

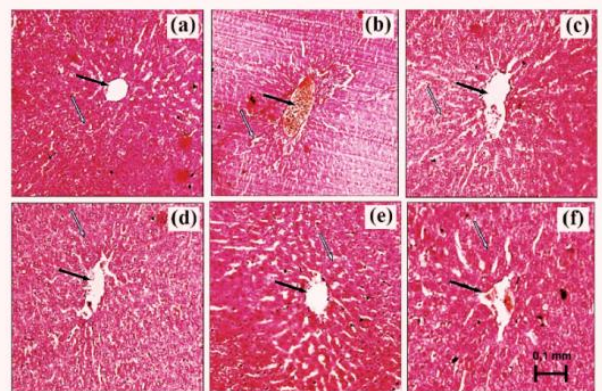

(B)

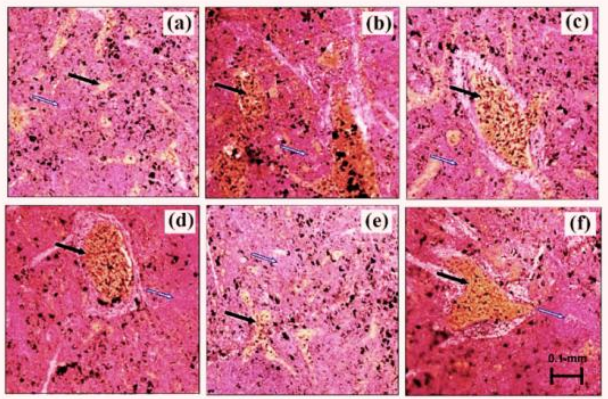

(D)

Fig. 3. Histological sections (Haematoxylin \& Eosin staining; X100) of (A) pancreases (solid arrows: pancreatic duct, and hollow arrows: islet of Langerhans), (B) livers (solid arrows: central vein and hollow arrows: hepatocyte), (C) kidneys (solid arrows: tubule and hollow arrows: glomerulus), and (D) Spleens (solid arrows: white pulp and hollow arrows: red pulp) of representative rats from each group. In all figures the ones marked with (a) represent a vehicle treated normal control rat, (b) represent a vehicle treated diabetic control rats, (c) represents a diabetic rat treated with AP (50 $\mathrm{mg} / \mathrm{kg} /$ day), (d) represents a diabetic rat treated with AP (100 mg/kg/day), (e) represent a diabetic rat treated with AP (200 mg/kg/day), and (f) represents a diabetic rat treated with Glibenclamide $(10 \mathrm{mg} / \mathrm{kg} / \mathrm{day})$. 
period the vehicle treated normal control group gained body weight $(5.00 \pm 0.30 \mathrm{~g})$, whereas vehicle treated diabetic control group lost $(7.67 \pm 0.62 \mathrm{~g})$. Beneficial effects of AP or of glibenclamide treatments on body weight changes, plasma glucose and insulin levels of diabetic rats are apparent from the data summarized in Table 1. These dose-dependent effects of AP were qualitatively analogous to the anti-diabetic drug glibenclamide. AP treatments dose-dependently reduces the elevated plasma levels of total cholesterol, triglycerides, and LDL, and increases the lowered plasma HDL levels observed in diabetic animals compared to diabetic control ( $p<0.05$; Fig. 2). These effects of AP treatments were also qualitatively analogous to those of glibenclamide treatment. Analogous were also the effects of AP treatments on elevated MDA levels, and reduced SOD and CAT activities in the all the three studied organs of diabetic rats (Table 2).

Representative pictures of histological slides of pancreas, liver, kidney and spleen of different groups of animals are shown in Fig. 3. Pancreatic tissues of vehicle treated diabetic rats had diminished glandular acini, islets of Langerhans (necrosis of beta cells), and atrophy in pancreatic duct. These pathologies were less severe in all AP or glibenclamide treated groups (Fig. 3A), and such protective effects of AP treatments were more prominent in the highest dose of AP treated animals. Such were not always the cases for other organ pathologies studied. No beneficial effects of glibenclamide treatment on hepatic pathologies encountered in diabetic animal were observed; whereas these pathologies were less severe, or almost absent, in different AP treated groups (Fig. 3B). Treatments with $50 \mathrm{mg} / \mathrm{kg} /$ day AP or with glibenclamide $(10 \mathrm{mg} / \mathrm{kg} / \mathrm{day})$ had no observable effects on renal pathologies observed in diabetic rats. However these pathologies observed in diabetic rats treated with 100 or $200 \mathrm{mg} / \mathrm{kg} /$ day were either less severe or completely absent (Fig. 3C). Although the spleen pathologies observed in the vehicle, or glibenclamide, or 50 or $100 \mathrm{mg} / \mathrm{kg} /$ day AP treated animals were qualitatively similar. The histological pictures of the spleens of the $200 \mathrm{mg} / \mathrm{kg} / \mathrm{day}$ AP treated animals were like those of vehicle treated normal laboratory rats (Fig. 3D).

\section{High fat fed obesity model}

During the 10-day treatment period the vehicle treated obese rats continued to gain more body weights, and consumed more food and water than the vehicle treated normal control ones ( $p$ $<0.05$ ). Plasma levels of glucose, insulin, total cholesterol, triglycerides, and LDL were all elevated in the obese control group, and the mean plasma HDL levels in this group were significantly $(p<0.05)$ lower than that of the normal control one. Results summarized in Table 3 and Fig. 4 revealed dosedependent beneficial effects of AP treatments against all these
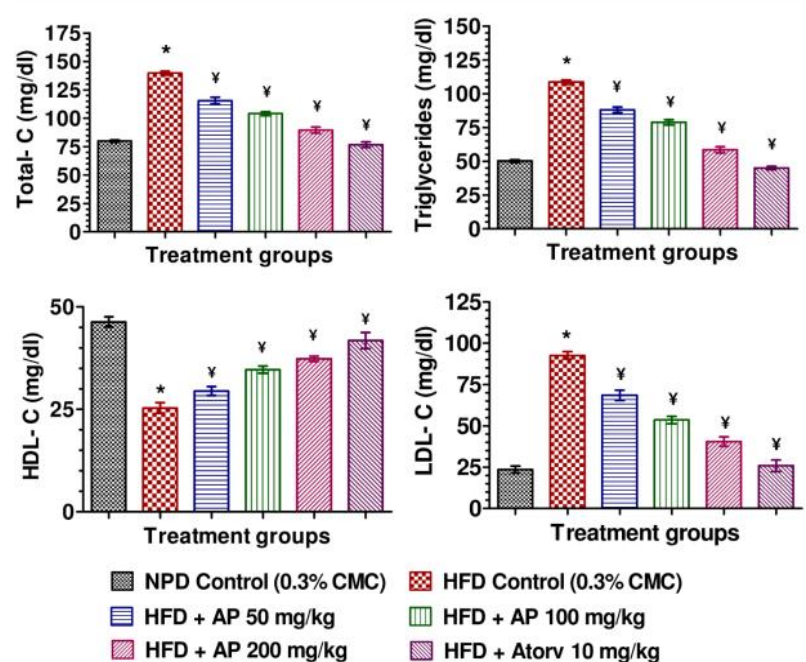

Fig. 4. Effect of Andrographis paniculata or of atorvastatin treatments on plasma lipid profile in high fat fed rats. AP: Andrographis paniculata; Atorv: Atorvastatin. ${ }^{*} p<0.05$ vs. normal control, ${ }^{¥} p<0.05$ vs. HFD control.

parameters. Qualitatively, all observed effects of AP hyperlipidemic drug atorvastatin.

\section{Fructose fed obesity model}

No statistically significant differences between the mean amounts of fructose consumed by the obese rats in different treatment groups were observed (data not shown). Data summarized in Table 4 revealed that the body weight gains of the obese control rats observed during the ten day treatment period were significantly $(p<0.05)$ higher than those of the AP or atorvastatin treated groups, and that these effects of drug treatments were accompanied with significantly $(p<0.05)$ lower plasma levels of glucose and insulin. Moreover, the elevated plasma levels of total cholesterol, triglycerides, and LDL and lower plasma levels of HDL observed in fructose fed rats were also dose-dependently antagonized by AP treatments (Fig. 5). All these observed effects of AP treatments were qualitatively analogous to that of the anti-hyperlipidemic drug atorvastatin.

\section{DISCUSSION}

The analytically well characterized Andrographis paniculata extract used in this study is rich in andrographolide (> 30\%) and is currently commercialized as an herbal alternative for trea

Table 3. Effects of Andrographis paniculata or of atorvastatin treatments on body weight gain, food intake, and fasting plasma glucose and insulin level in high fat fed obese rats

\begin{tabular}{|c|c|c|c|c|}
\hline Treatment group & Body weight gain (g) & Food intake (g/rat) & $\begin{array}{l}\text { Fasting blood glucose } \\
(\mathrm{mg} / \mathrm{dl})\end{array}$ & Plasma insulin $(\mu \mathrm{U} / \mathrm{ml})$ \\
\hline NPD Control (0.3\% CMC) & $3.92 \pm 0.53$ & $11.08 \pm 0.53$ & $89.68 \pm 1.53$ & $18.03 \pm 0.29$ \\
\hline HFD Control (0.3\% CMC) & $45.83 \pm 3.21^{*}$ & $17.33 \pm 0.66^{*}$ & $290.43 \pm 1.45^{*}$ & $59.32 \pm 1.13^{*}$ \\
\hline $\mathrm{HFD}+\mathrm{AP} 50 \mathrm{mg} / \mathrm{kg}$ & $38.50 \pm 2.69^{¥}$ & $14.00 \pm 0.58^{¥}$ & $172.80 \pm 2.24^{¥}$ & $41.14 \pm 1.56^{¥}$ \\
\hline $\mathrm{HFD}+\mathrm{AP} 100 \mathrm{mg} / \mathrm{kg}$ & $30.00 \pm 3.45^{¥}$ & $13.33 \pm 0.67^{¥}$ & $146.18 \pm 1.78^{*}$ & $35.72 \pm 0.79^{¥}$ \\
\hline $\mathrm{HFD}+\mathrm{AP} 200 \mathrm{mg} / \mathrm{kg}$ & $13.17 \pm 1.38^{¥}$ & $13.00 \pm 0.58^{¥}$ & $130.43 \pm 2.53^{¥}$ & $25.21 \pm 0.74^{¥}$ \\
\hline $\mathrm{HFD}+$ Atorv $10 \mathrm{mg} / \mathrm{kg}$ & $7.67 \pm 0.71^{¥}$ & $12.17 \pm 0.48^{*}$ & $117.53 \pm 3.08^{¥}$ & $21.54 \pm 0.73^{¥}$ \\
\hline
\end{tabular}

AP: Andrographis paniculata; Atorv: Atorvastatin. ${ }^{*} p<0.05$ vs. normal control, ${ }^{\ddagger} p<0.05$ vs. HFD control. 

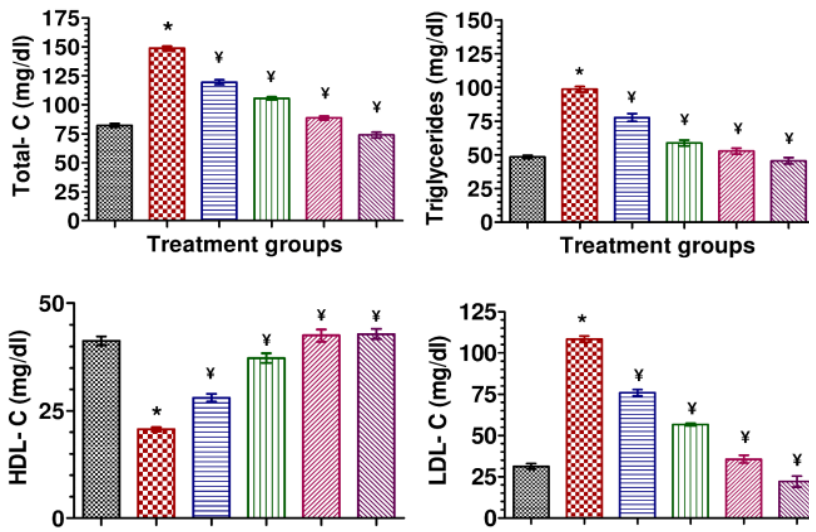

Treatment groups

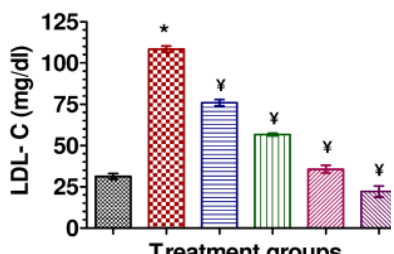

Normal Control $(0.3 \%$ CMC)

目 FF + AP $50 \mathrm{mg} / \mathrm{kg}$

FF + AP $200 \mathrm{mg} / \mathrm{kg}$

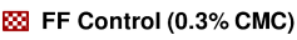

血 $\mathrm{FF}+\mathrm{AP} 100 \mathrm{mg} / \mathrm{kg}$

$\mathbb{F F}+$ Atorv $10 \mathrm{mg} / \mathrm{kg}$

Fig. 5. Effect of Andrographis paniculata or of atorvastatin treatments on plasma lipid profile in high fat fed rats. AP: Andrographis paniculata; Atorv: Atorvastatin. ${ }^{*} p<0.05$ vs. normal control, ${ }^{¥} p<0.05$ vs. HFD control.

tments of common cold and other respiratory tract infections. Earlier observations in our laboratories have revealed that daily oral AP doses up to $800 \mathrm{mg} / \mathrm{kg}$ administered for ten consecutive days are well tolerated by laboratory animals, and that its significant dose-dependent behavioral effects in rodents are observed only after its $100 \mathrm{mg} / \mathrm{kg}$ or higher daily doses. Our results revealed that even ten oral daily $50 \mathrm{mg} / \mathrm{kg}$ doses of AP significantly reduced blood glucose clearance in glucose tolerance test in normal laboratory rats, and this effect of the extract increased after higher doses. However, the effects of AP treatments observed after its highest dose tested $(200 \mathrm{mg} / \mathrm{kg})$ were qualitatively much lower than that observed for 10 $\mathrm{mg} / \mathrm{kg} /$ day dose of the standard anti-diabetic drug glibenclamide. Moreover, unlike in the glibenclamide treated group, blood glucose decay curves observed between 30 and $120 \mathrm{~min}$ after glucose load in all AP treated groups were always parallel to that observed in normal control group (Fig. 1). This observation indicates that the mode and site of action of AP in regulating glucose metabolism is most probably unlike those of glibenclamide.

Observations made in the type- 2 diabetes model revealed again that $50 \mathrm{mg} / \mathrm{kg} /$ day treatment regimen of AP is effective in reducing all metabolic alterations observed in vehicle treated hyperglycemic and hypo-insulinemic animals and that these observed effects of the extract always increased with its increasing doses. All observed effects of AP on every metabolic parameter assayed were dose-dependent, and were qualitatively analogous to those observed in the glibenclamide treated diabetic animals. However, the histopathological observations made in drug treated diabetic animals were not similar. Although the pancreatic pathologies were less severe in both AP or glibenclamide treated groups, such were not the cases in liver, spleen, and kidney. Unlike in the AP treated groups, no protective effects of glibenclamide treatments against the pathologies of these three later mentioned organs were observed. These observations reaffirm that the mode(s) and site(s) of actions of AP are unlike those of pancreatic insulin stimulating agents like glibenclamide. In any case as previous study (Zhang and Tan, 2000a; Zhang and Tan 2000b; Yu et al., 2003), the observations made in this model clearly reveal that daily oral administration of AP is not only effective in compensating metabolic abnormalities and bodyweight losses in diabetic animals, but also afford protection against free radicals mediated organ damages.

Diabesity associated hyperglycemia and hyperlipidemia are well recognized risk factors of cardiovascular diseases (Braun et al., 2013). Reported observations made in the type- 2 diabetes model clearly revealed dose-dependent anti-hyperglycemic and anti-hyperlipidemic effects of AP, and during the course of our studies two reports revealing such effects of very high doses of another type of Andrographis paniculata extract, or of fairly low doses of pure andrographolide or of neoandrographolide in other rodent models have appeared (Nugroho et al., 2013; Yang et al., 2013). Observed effects of AP on hyperglycemia and hyperlipidemia in both the obesity models used in our studies were quite analogous to those observed in the type- 2 diabetes model. However, body weight gains and circulating insulin levels in the AP treated type- 2 diabetes rats were higher than those of the vehicle treated ones, whereas both weight gains and insulin levels in AP treated obese rats were lower than those observed in vehicle treated obese rats. These observations strongly suggest that the effects of AP treatments on insulin levels and body weights depend largely on metabolic status of animals. Further, it indicates that modulating effects of the extract on biological mechanisms and processes regulating insulin secretion and metabolism could as well be involved in its modes of actions. Since AP and several of its components modulates the productions of diverse mediators of inflammation (Chandrasekaran et al., 2010; Chandrasekaran et al., 2011), we speculate that the observed therapeutically interesting anti-diabetic and anti-obesity effects of AP are due to its anti-inflammatory activities. Efforts to experimentally verify this possibility are now progressing in our laboratories.

Ultimate goal of our efforts to define therapy relevant pharmacological activity profile of AP is to experimentally verify the possibility whether it could as well be an herbal alternative for prevention and treatments of diverse spectrums of mental health problems commonly encountered in obese

Table 4. Effect of AP or of atorvastatin treatments on body weight gain and fasting plasma glucose and insulin level in fructose fed obese rats

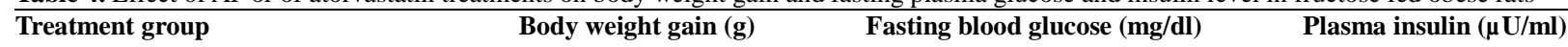

\begin{tabular}{|c|c|c|c|}
\hline NPD Control (0.3\% CMC) & $5.33 \pm 0.58$ & $90.97 \pm 1.52$ & $18.02 \pm 0.28$ \\
\hline FF Control $(0.3 \%$ CMC $)$ & $30.67 \pm 2.07 *$ & $184.11 \pm 1.84 *$ & $58.53 \pm 1.23 *$ \\
\hline $\mathrm{FF}+\mathrm{AP} 50 \mathrm{mg} / \mathrm{kg}$ & $22.83 \pm 3.04^{¥}$ & $165.16 \pm 2.34^{¥}$ & $40.62 \pm 1.32^{¥}$ \\
\hline $\mathrm{FF}+\mathrm{AP} 100 \mathrm{mg} / \mathrm{kg}$ & $13.17 \pm 1.89^{¥}$ & $138.66 \pm 2.38^{¥}$ & $30.53 \pm 0.82^{¥}$ \\
\hline$\overline{\mathrm{FF}}+\mathrm{AP} 200 \mathrm{mg} / \mathrm{kg}$ & $9.00 \pm 1.32^{¥}$ & $107.80 \pm 2.10^{¥}$ & $21.54 \pm 0.83^{¥}$ \\
\hline$\overline{\mathrm{FF}}+$ Atorv $10 \mathrm{mg} / \mathrm{kg}$ & $4.67 \pm 0.76^{\ddagger}$ & $125.48 \pm 2.44^{¥}$ & $25.20 \pm 0.71^{¥}$ \\
\hline
\end{tabular}

$\overline{\mathrm{AP}}$ : Andrographis paniculata; Atorv: Atorvastatin. ${ }^{*} p<0.05$ vs. normal control, ${ }^{\ddagger} p<0.05$ vs. FF control. 
diabetic patients. Patients with anxiety disorders and depression are more prone to increased dyslipidemia and obesity risk (van Reedt Dortland et al., 2013a), and close association between chronic low grade inflammation and such co-morbidities is well documented (van Reedt Dortland et al., 2013b). Since AP contains andrographolide and other anti-inflammatory molecules, and its anti-stress and other brain function modulating effects of AP has been observed in our earlier studies (Thakur et al., 2013), we are now concentrating our efforts to define its psychopharmacological activity profile in animal models of diabetes and obesity.

Our results revealed that the effects of repeated daily intake of Andrographis paniculata extracts on plasma insulin levels and body weight gain depend on the metabolic status of the animals, and that AP could as well be a therapeutic possibility for combating life threatening metabolic disorders commonly associated with, or caused by, disturbances of glucose and lipid metabolism. In this respect, it was interesting to note that plasma insulin levels of type- 2 diabetic rats increased after AP treatments, whereas the elevated plasma insulin levels observed in both the obese rat models were suppressed in the extract treated obese groups. Thus AP seems to be a pharmacologically novel type of regulator of glucose homeostasis with some functional commonalities with the therapeutically used antihyperglycemic or anti-hyperlipidemic drugs. However, further studies will be necessary to confirm this possibility, and to verify whether modulations of oxidative processes are also involved in its observed suppressive effects on body weight gains of obese rats.

In conclusion, the results of the present study demonstrate that Andrographis paniculata extract rich in andrographolide could be a pharmaco-therapeutic alternative for combating diabesity associated metabolic syndromes.

\section{ACKNOWLEDGEMENTS}

AKT graciously acknowledged the Department of Science and Technology, Government of India, New Delhi for awarding INSPIRE Fellowship (IF110595). Authors would like to acknowledge Natural Remedies Pvt. Ltd., Bangalore for providing complementary sample of standardized extract of Andrographis paniculata.

\section{CONFLICT OF INTEREST}

The authors do not have any conflict of interest in the present study.

\section{REFERENCES}

Agarwal R, Sulaiman SA, Mohamed M. Open label clinical trial to study adverse effects and tolerance to dry powder of the aerial part of Andrographis paniculata in patients type 2 with diabetes mellitus. Malays J Med Sci. 2005;12:13-19.

Al-Bayaty FH, Abdulla MA, Abu Hassan MI, Ali HM. Effect of Andrographis paniculata leaf extract on wound healing in rats. Nat Prod Res. 2012;26:423-429

Beeler JA, Frazier CR, Zhuang X. Putting desire on a budget: dopamine and energy expenditure, reconciling reward and resources. Front Integr Neurosci. 2012;6:49.
Bensky D, Gamble A. Andrographis paniculata: Chinese Herbal Medicine Materia Medica. (Washington, USA: Eastland Press), 1986.

Braun J, Bopp M, Faeh D. Blood glucose may be an alternative to cholesterol in CVD risk prediction charts. Cardiovasc Diabetol. 2013;12:24.

Burgos RA, Hancke JL, Bertoglio JC, Aguirre V, Arriagada S, Calvo M, Cáceres DD. Efficacy of an Andrographis paniculata composition for the relief of rheumatoid arthritis symptoms: a prospective randomized placebo-controlled trial. Clin Rheumatol. 2009;28:931-946.

Chandrasekaran CV, Gupta A, Agarwal A. Effect of an extract of Andrographis paniculata leaves on inflammatory and allergic mediators in vitro. J Ethnopharmacol. 2010;129:203207.

Chandrasekaran CV, Thiyagarajan P, Deepak HB, Agarwal A. In vitro modulation of LPS/calcimycin induced inflammatory and allergic mediators by pure compounds of Andrographis paniculata (King of bitters) extract. Int Immunopharmacol. 2011;11:79-84.

Chandrasekaran CV, Thiyagarajan P, Sundarajan K, Goudar KS, Deepak M, Murali B, Allan JJ, Agarwal A. Evaluation of the genotoxic potential and acute oral toxicity of standardized extract of Andrographis paniculata (KalmCold). Food Chem Toxicol. 2009;47:1892-1902.

Chao WW, Lin BF. Isolation and identification of bioactive compounds in Andrographis paniculata (Chuanxinlian). Chin Med. 2010;5:17.

Chatterjee SS, Kumar V. Holistic psychopharmacology and promiscuous plants and principles of Ayurveda. Am J Plant Sci. 2012;3:1015-1021.

Colagiuri S. Diabesity: therapeutic options. Diabetes Obes Metab. 2010;12:463-473.

du Vigneaud V, Karr WG. Carbohydrate utilization: I. Rate of disappearance of d-glucose from the blood. J Biol Chem. 1925;66:281-300.

Farag YM, Gaballa MR. Diabesity: an overview of a rising epidemic. Nephrol Dial Transplant. 2011;26:28-35.

Friedewald WT, Levy RI, Fredrickson DS. Estimation of the concentration of low-density lipoprotein cholesterol in plasma, without use of the preparative ultracentrifuge. Clin Chem. 1972;18:499-502.

Govindarajan R, Vijayakumar M, Pushpangadan P. Antioxidant approach to disease management and the role of 'Rasayana' herbs of Ayurveda. J Ethnopharmacol. 2005;99:165-178.

Husain GM, Chatterjee SS, Singh PN, Kumar V. Hypolipidemic and antiobesity-like activity of standardised extract of Hypericum perforatum L. in Rats. ISRN Pharmacol. 2011a; 2011: 505247.

Husain GM, Singh PN, Singh RK, et al. Antidiabetic activity of standardized extract of Quassia amara in nicotinamidestreptozotocin-induced diabetic rats. Phytother Res. 


\section{1b;25:1806-1812.}

Jalal R, Bagheri SM, Moghimi A, Rasuli MB. Hypoglycemic effect of aqueous shallot and garlic extracts in rats with fructose-induced insulin resistance. J Clin Biochem Nutr. 2007;41:218-223.

Kakkar P, Das B, Viswanathan PN. A modified spectrophotometric assay of superoxide dismutase. Indian $\mathbf{J}$ Biochem Biophys. 1984;21:130-132.

Lim JC, Chan TK, Ng DS, Sagineedu SR, Stanslas J, Wong WS. Andrographolide and its analogues: versatile bioactive molecules for combating inflammation and cancer. Clin Exp Pharmacol Physiol. 2012;39:300-310.

Luck H. Methods of enzymatic analysis. In, Bergmeyer HU ed. (Verlag Chemie, Weinheim and New York, USA: Academic Press), pp. 885-888, 1963.

Masiello P, Broca C, Gross R, Roye M, Manteghetti M, Hillaire-Buys D, Novelli M, Ribes G. Experimental NIDDM: development of a new model in adult rats administered streptozotocin and nicotinamide. Diabetes. 1998;47:224-229.

Mishra K, Dash AP, Swain BK, Dey N. Anti-malarial activities of Andrographis paniculata and Hedyotis corymbosa extracts and their combination with curcumin. Malar J. 2009;8:26.

Nugroho AE, Andrie M, Warditiani NK, Siswanto E, Pramono S, Lukitaningsih E. Antidiabetic and antihiperlipidemic effect of Andrographis paniculata (Burm. f.) Nees and andrographolide in high-fructose-fat-fed rats. Indian $\mathbf{J}$ Pharmacol. 2012;44:377-381.

Ohkawa H, Ohishi N, Yagi K. Assay for lipid peroxides in animal tissues by thiobarbituric acid reaction. Anal Biochem. 1979;95:351-358.

Shen T, Yang WS, Yi YS, Sung GH, Rhee MH, Poo H, Kim MY, Kim KW, Kim JH, Cho JY. AP-1/IRF-3 Targeted AntiInflammatory Activity of Andrographolide Isolated from Andrographis paniculata. Evid Based Complement Alternat Med. 2013;2013:210736.

Sims EA, Danforth E Jr, Horton ES, Bray GA, Glennon JA, Salans LB. Endocrine and metabolic effects of experimental obesity in man. Recent Prog Horm Res. 1973;29:457-496.

Srinivasan K, Viswanad B, Asrat L, Kaul CL, Ramarao P. Combination of high-fat diet-fed and low-dose streptozotocintreated rat: a model for type 2 diabetes and pharmacological screening. Pharmacol Res. 2005;52:313-320.

Subramanian R, Zaini Asmawi M, Sadikun A. A bitter plant with a sweet future? A comprehensive review of an oriental medicinal plant: Andrographis paniculata. Phytochemistry Rev. 2012;11:39-75.

Subramanian R, Zaini Asmawi M, Sadikun A. Effect of ethanolic extract of Andrographis paniculata (Burm. F.) Nees on a combination of fat-fed and low dose streptozotocin induced chronic insulin resistance in rats. Diabetol Croat. 2008;37:13-22.

Thakur AK, Chatterjee SS, Kumar V.
Neuropsychopharmacology of a therapeutically used Andrographis paniculata extract: a preclinical study. Oriental Pharm Exp Med. 2013. doi: 10.1007/s13596-013-0140-4.

Thakur M, Weng A, Fuchs H, Sharma V, Bhargava CS, Chauhan NS, Dixitc VK, Bhargava S. Rasayana properties of Ayurvedic herbs: Are polysaccharides a major contributor. Carbohydr Polymers. 2012;87:3-15.

van Reedt Dortland AK, Giltay EJ, van Veen T, Zitman FG, Penninx BW. Longitudinal relationship of depressive and anxiety symptoms with dyslipidemia and abdominal obesity. Psychosom Med. 2013a;75:83-89.

van Reedt Dortland AK, Vreeburg SA, Giltay EJ, Licht CM, Vogelzangs N, van Veen T, de Geus EJ, Penninx BW, Zitman FG. The impact of stress systems and lifestyle on dyslipidemia and obesity in anxiety and depression. Psychoneuroendocrinology. 2013b;38:209-218.

Wu KK, Huan Y. Streptozotocin-induced diabetic models in mice and rats. Curr Protoc Pharmacol. 2008;5:47.

Xu J, Li Z, Cao M, Zhang H, Sun J, Zhao J, Zhou Q, Wu Z, Yang L. Synergetic effect of Andrographis paniculata polysaccharide on diabetic nephropathy with andrographolide. Int J Biol Macromol. 2012;51:738-742.

Yang T, Shi HX, Wang ZT, Wang CH. Hypolipidemic effects of andrographolide and neoandrographolide in mice and rats. Phytother Res. 2013;27:618-623.

Yu BC, Hung CR, Chen WC, Cheng JT. Antihyperglycemic effect of andrographolide in streptozotocin-induced diabetic rats. Planta Med. 2003;69:1075-1079.

Zhang XF, Tan BK. Anti-diabetic property of ethanolic extract of Andrographis paniculata in streptozotocin-diabetic rats. Acta Pharmacol Sin. 2000a;21:1157-1164.

Zhang XF, Tan BK. Antihyperglycaemic and anti-oxidant properties of Andrographis paniculata in normal and diabetic rats. Clin Exp Pharmacol Physiol. 2000b;27:358-363. 